\title{
Identification of a functional SNP in an asthma gene: IL1RL1
}

\author{
Loubna Akhabir*, Andrew Sandford \\ From Allergen NCE Inc.'s Fifth Annual Research Conference: Innovation from Cell to Society \\ Québec City, QC, Canada. 7-9 February 2010
}

\begin{abstract}
Background
Our aim is to identify causal variants for the IL1RL1 gene previously associated with asthma and related phenotypes as well as perform functional assays to uncover the mechanism underlying its involvement in the disease pathogenesis. IL1RL1 has been shown to be sufficient to induce experimental allergic airway inflammation using transgenic and knockdown mouse models. Its expression has been shown to increase in murine and human asthmatic lungs; the ligand for IL1RL1 is Interleukin-33 (IL33). The signaling cascade resulting from the binding of TSLP and IL33 is crucial in eosinophilic inflammation characteristic of asthma. The IL1RL1 gene lies in chromosome 2 in the midst of a cytokine gene cluster with IL1R1, IL1RL2, IL18R1 and IL18RAP: all encoding for proteins involved in the immune response characteristic of asthma. The region is in relatively high linkage disequilibrium, thus an excellent candidate for narrowing down the asthma association signal to one or more causal SNPs.
\end{abstract}

\section{Methods}

Firstly, a putative causal SNP is identified based on previous association data, or linkage disequilibrium with associated SNPs, conservation scores and putative binding of regulatory proteins.

DNA samples from asthmatics and controls are then genotyped for the candidate SNP using Taqman technology in order to relate genotypes to potential alteration of gene expression.

Gene expression assays will be performed to compare levels of expression between the different genotypes as well as between the two SNP alleles. These real timepolymerase chain reaction (RT-PCR) experiments will

\footnotetext{
* Correspondence: loubna.akhabir@hli.ubc.ca

UBC James Hogg Research Centre, Providence Heart+Lung Institute, Vancouver, BC, Canada
}

be conducted for both IL1RL1 isoforms in order to also assess their differential expression depending on our candidate SNP genotype. If changes in expression are observed, we will perform electrophoretic mobility shift assays in order to test if the differential expression is due to the differential binding of a regulatory protein depending on the SNP allele. In order to further confirm that the SNP site is in an important region for gene expression regulation we will perform formaldehyde-assisted isolation of regulatory elements (FAIRE); a method which discriminates between DNA sequences depending on the presence or lack of nucleosome structures. The absence of nucleosome indicates that the region is active and accessible to regulatory elements and thus important for gene regulation.

\section{Findings}

We have selected the IL1RL1 SNP rs1420101 based on the fact that it was the most significant signal in a genome-wide study about eosinophil counts and the same SNP associated with asthma in ten populations in the same study. During the optimization phase of our gene expression assays, we confirmed differential expression of the IL1RL1 isoforms in RNA samples from blood of asthmatic children as well as controls. The next step is to relate that differential expression to the SNP genotype as well as continue with RT-PCR to compare allele-specific expression.

\section{Conclusions and relevance}

The overall objective of this research is to enhance our understanding of the pathogenesis of asthma by narrowing down genetic association signals to specific causal variants. Not only will this strengthen the evidence for IL1RL1 being an asthma gene but it will also help untangle the association signal from this region. Reaching a greater understanding of the molecular 
pathogenesis of asthma will eventually pave the way for novel therapies targeting the source of inflammation rather than life-long therapies aimed at dampening inflammation and easing symptoms.

Published: 26 November 2010

doi:10.1186/1710-1492-6-S3-P1

Cite this article as: Akhabir and Sandford: Identification of a functional SNP in an asthma gene: IL1RL1. Allergy, Asthma \& Clinical Immunology 2010 6(Suppl 3):P1.

Submit your next manuscript to BioMed Central and take full advantage of:

- Convenient online submission

- Thorough peer review

- No space constraints or color figure charges

- Immediate publication on acceptance

- Inclusion in PubMed, CAS, Scopus and Google Scholar

- Research which is freely available for redistribution

Submit your manuscript at www.biomedcentral.com/submit 